\title{
Diversity of UV Reflection Patterns in Odonata
}

\author{
Ryo Futahashi* \\ Bioproduction Research Institute, National Institute of Advanced Industrial Science and Technology (AIST), Tsukuba, Japan
}

\section{OPEN ACCESS}

Edited by:

Marcus Kronforst,

The University of Chicago,

United States

Reviewed by:

Doekele G. Stavenga

University of Groningen, Netherlands

David Outomuro,

University of Cincinnati, United States

*Correspondence:

Ryo Futahashi

ryo-futahashi@aist.go.jp

Specialty section:

This article was submitted to

Evolutionary Developmental Biology,

a section of the journal

Frontiers in Ecology and Evolution

Received: 29 February 2020

Accepted: 02 June 2020

Published: 09 July 2020

Citation:

Futahashi R (2020) Diversity of UV Reflection Patterns in Odonata.

Front. Ecol. Evol. 8:201. doi: 10.3389/fevo.2020.00201
Dragonflies and damselflies (Odonata) are large-eyed diurnal insects that exhibit a variety of color patterns on their wings and/or bodies. Because Odonata can perceive light with wavelengths extending from ultraviolet (UV) to red, the color patterns with UV reflection can be visually recognized by each other. The UV reflection patterns of Odonata have been investigated by using a UV camera and optically measuring the reflectance of body and wing surfaces. The UV reflection of Odonata can be classified into three classes, namely, iridescent UV reflection, wax-based UV reflection, and UV reflection by epidermal granules. In this review, I present UV images of these three classes and representative examples of reflectance. Among the Odonata with colorful iridescent wings consisting of multilayer structures, some species (e.g., Chalcopteryx scintillans) predominantly reflect UV light, whereas other species (e.g., Calopteryx japonica) mostly reflect light at wavelengths above $400 \mathrm{~nm}$. Whitish wax (called pruinescence) on the body and/or wing surface strongly reflects light including UV, due to the lightscattering fine structures produced by the wax. The chemical composition of the dragonfly's abdominal UV-reflective wax differs from previously identified waxes of other organisms. The blue-tailed damselflies Ischnura species exhibit immature-adult-specific UV reflection by the pteridine pigment-based selective light scattering and absorption. Iridescent coloration and wax-based color changes are generally important for mate recognition and male-male competition in Odonata, although the ecological importance of UV reflection remains largely unknown except for few examples in damselflies.

Keywords: Odonata, dragonfly, damselfly, color, UV reflection, multilayer, wax, pigment

\section{INTRODUCTION}

Dragonflies and damselflies (Odonata) are large-eyed diurnal insects, and adults exhibit a variety of color patterns on their wings and/or bodies. These color patterns often represent sexual color dimorphism, color transition via sexual maturation, and intraspecific color polymorphisms within the same sex (Tillyard, 1917; Corbet, 1999; Bybee et al., 2016; Futahashi, 2016). Both dragonflies (suborders Anisozygoptera and Anisoptera) and damselflies (suborder Zygoptera) possess a remarkably large number of visual opsin genes (Futahashi et al., 2015; Suvorov et al., 2017), and electrophysiological studies have shown that Odonata species can perceive light with wavelengths extending from ultraviolet (UV) to red (Meinertzhagen et al., 1983; Yang and Osorio, 1991; Labhart and Nilsson, 1995; Huang et al., 2014; Futahashi et al., 2015), suggesting that the UV reflection patterns can be visually recognized by each other. 
The UV reflection pattern of Odonata has been classically investigated using a UV camera, and it has been reported that several Libellulidae dragonflies coated with a whitish wax consistently exhibit UV reflection (Robey, 1975; Silberglied, 1979; Harris et al., 2011; Futahashi et al., 2019). Hilton (1986) comprehensively investigated UV reflection using dried specimens preserved in a museum. Even though 343 species belonging to 16 families were investigated, UV reflection was detected only in one damselfly species, namely Euphaea amphicyana (Euphaeidae). As pointed out in this paper, one of the reasons that UV reflection was not observed in almost all the species was that their body color was changed and the surface wax was destroyed by acetone treatment for preparing the dried specimens. Harris et al. (2011) used fresh specimens of 10 species belonging to 4 families and found that the UV reflection pattern often differed between species and sexes, although it was difficult to evaluate the intensity of the UV reflection due to the low UV sensitivity of the equipment.

Aside from the observation using a UV camera, optical measurements of the reflectance of wing and body surfaces have been conducted, and UV reflection has been detected in several Odonata species (Robertson, 1984; Schultz and Fincke, 2009; Guillermo-Ferreira et al., 2014, 2015, 2019; Nixon et al., 2015, 2017; Futahashi et al., 2019; Henze et al., 2019). The UV reflection of Odonata can be classified into the following three classes: iridescent UV reflection, wax-based UV reflection, and UV reflection by epidermal granules. In this review, I show UV photographs of these three classes taken with a high-sensitivity camera (Sony A7S, IDAS UV-VIS mod) and a UV filter (IDAS-U) in the field, as well as representative examples of reflectance from previous reports. I also aim to review the mechanism underlying the UV reflection and its ecological significance.

\section{EXAMPLES AND MECHANISMS OF IRIDESCENT UV REFLECTION}

Some Odonata species have colorful iridescent wings and/or bodies (Figures 1A-C), and the spectral reflectance and cuticular structures of the iridescent coloration have been reported (Fitzstephens and Getty, 2000; Vukusic et al., 2004; Hariyama et al., 2005; Schultz and Fincke, 2009; Kuitunen and Gorb, 2011; Stavenga et al., 2012; Nixon et al., 2013, 2015; GuillermoFerreira et al., 2014, 2015, 2019; Appel et al., 2015). In the iridescent coloration of the wings, some species (e.g., Chalcopteryx scintillans, Polythoridae) predominantly reflect UV light (Figures 2A,B), whereas other species (e.g., Calopteryx japonica, Calopterygidae, Figures 1C,D) mostly reflect light at wavelengths above $400 \mathrm{~nm}$ (Figure 2B; Stavenga et al., 2012; Guillermo-Ferreira et al., 2019). In the flutterer dragonfly Rhyothemis fuliginosa (Libellulidae), bluish male wings strongly reflected UV light (Figure 1A), while greenish female wings scarcely reflected UV light (Figure 1B). Like other insects, the difference in reflectance of the iridescent coloration is primarily attributed to the difference in the multilayer structure that contains several layers with alternating high and low electron density near the wing surface. The resulting reflected wavelength is dependent on several factors, such as the thickness of the dense layers, the interval between layers, the refractive index of the layers, and the angles of refraction in layers (Kinoshita and Yoshioka, 2005; Stavenga et al., 2011). In general, a thinner multilayer interval produces shorter peaks in the reflected light. In the black-winged damselfly Calopteryx maculate (Calopterygidae), the iridescent coloration of male wings can be manipulated experimentally by the changes in diet. The bluish males (resulting from higher food consumption) have thinner layers than the greenish males (Fitzstephens and Getty, 2000). In the damselfly Matronoides cyaneipennis (Calopterygidae), males have bluish iridescent coloration on the dorsal hindwings and greenish iridescent coloration on the ventral hindwings (Nixon et al., 2013). There are five layers at both surfaces of the wings; the only difference is that the second layer of the dorsal surface is thinner than that of the ventral surface. Theoretically modeled reflectance shows that this small difference results in a significant change in the peak reflection wavelength (Nixon et al., 2013).

In the flutterer dragonfly Rhyothemis resplendens (Libellulidae), the multilayer structure is obviously wrinkled, which causes the light to be scattered at a broader angle than the unwrinkled multilayer structure (Nixon et al., 2015). In addition, the surface wax plays an important role in color tuning and angle-dependent light scattering (Kuitunen and Gorb, 2011; Guillermo-Ferreira et al., 2015, 2019). In the neotropical morpho dragonfly Zenithoptera lanei (Libellulidae), the surface wax of the dorsal wings increases brightness and reduces chroma (Guillermo-Ferreira et al., 2015). In the Amazonian damselfly C. scintillans, the surface wax of the dorsal wings provides specific angle-dependent light scattering and antireflective properties (Guillermo-Ferreira et al., 2019).

\section{EXAMPLES AND MECHANISMS OF WAX-BASED UV REFLECTION}

A wide variety of Odonata species are partly coated with whitish or pale bluish wax (called pruinescence) on body surfaces of the abdomen, thorax, head, and wings (Figures 1E-G, 2A). Wax secreted from numerous fine ducts penetrating the cuticle layer increases during adult maturation and is generally welldeveloped in males than in females, resulting in wax-based, sex-specific color changes (Tillyard, 1917; Jacobs, 1955; Robey, 1975; Gorb, 1995; Corbet, 1999; Futahashi et al., 2019). In general, mature males secrete dense wax predominantly on the dorsal region, whereas mature females secrete pruinose wax mostly on the ventral region and often become slightly whitish with aging (Gorb, 1995; Harris et al., 2011; Futahashi et al., 2019). In the suborder Zygoptera, species with whitish wax are found in most families, whereas in the suborder Anisoptera, species with conspicuous whitish wax are found predominantly in the family Libellulidae (Corbet, 1999). River-dwelling dragonfly species (e.g., Epiophlebiidae, Gomphidae, Chlorogomphidae, Cordulegastridae, and Macromiidae) scarcely secrete whitish wax with a few exceptions like Gomphurus lynnae (Gomphidae) (Paulson, 1983; Figure 2A). Weak pruinose wax on the ventral 

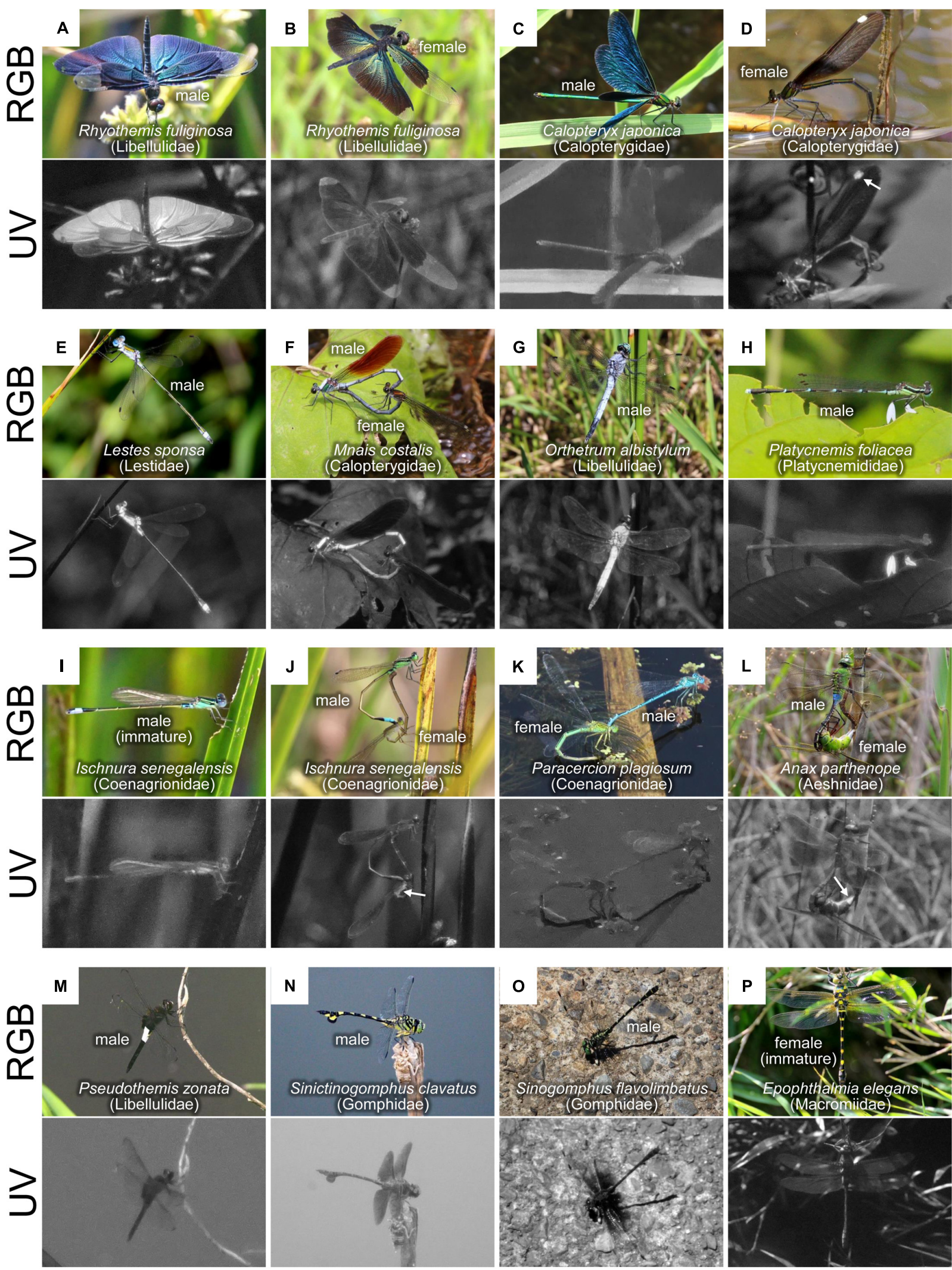

FIGURE 1 | Color pattern diversity in dragonflies as visualized in red, green, blue (RGB), and ultraviolet (UV) light. (A-P) Each image was photographed normally (upper) or through a UV filter (lower) in the field. Sex and species names are provided for each image. 

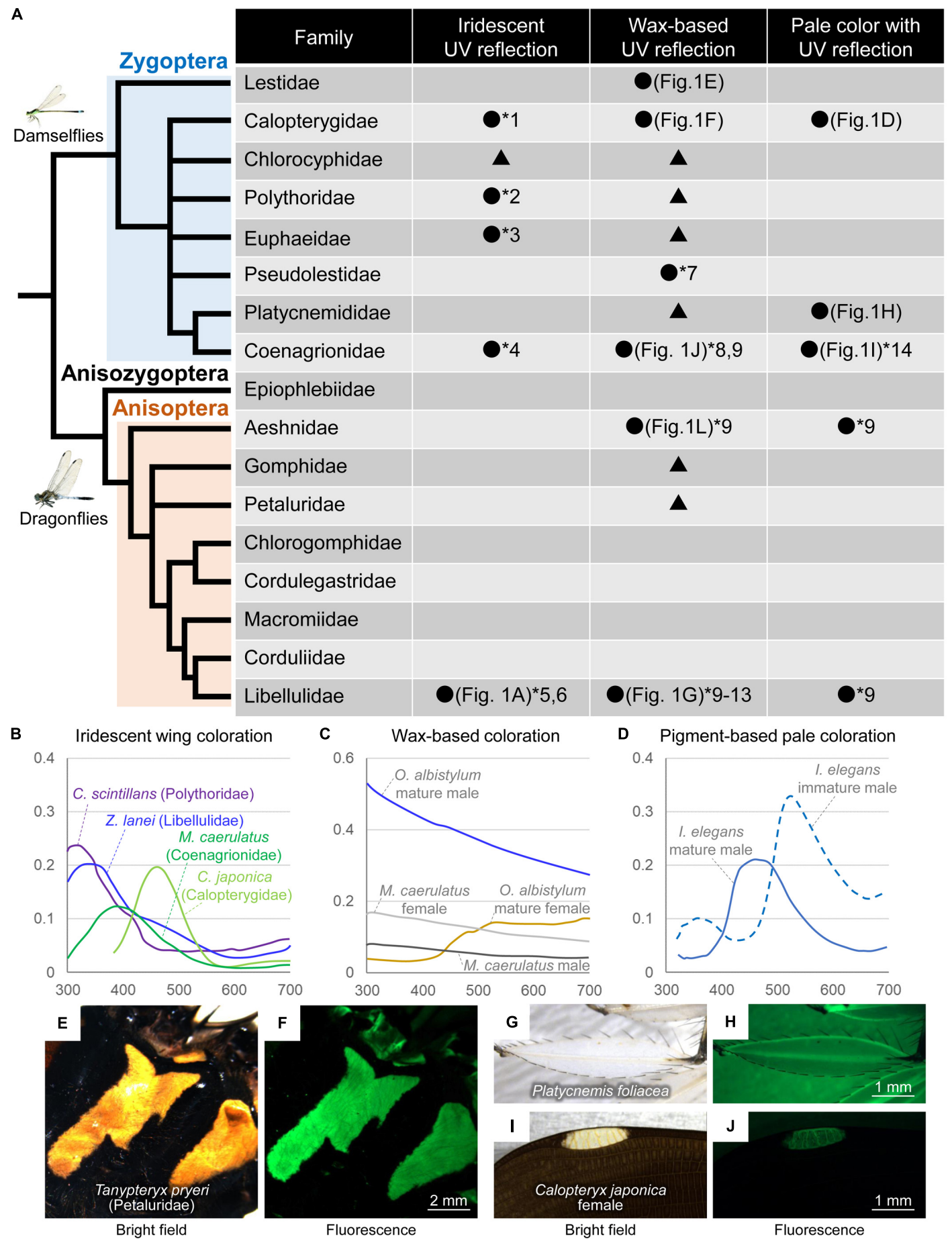

FIGURE 2 | (A) Summary of UV reflection patterns in Odonata. The Odonata phylogeny is modified from Bybee et al. (2016). Black circles and numbers indicate that UV reflection has been confirmed due to reflectance and/or UV images as follows: *1, Guillermo-Ferreira et al., 2014 Reflectance; *2, Guillermo-Ferreira et al., 2019 Reflectance; `3, Hilton, 1986 UV images; *4, Schultz and Fincke, 2009 Reflectance; *5, Nixon et al., 2015 Reflectance; *6, Guillermo-Ferreira et al., 2015 Reflectance; '7, Nixon et al., 2017 Reflectance; *8, Schultz and Fincke, 2009 Reflectance; *9, Harris et al., 2011 UV images; *10, Robey, 1975 UV images; *11, Silberglied, 1979 UV images; *12, Robertson, 1984 Reflectance; *13, Futahashi et al., 2019 Reflectance and UV images; *14, Henze et al., 2019 Reflectance. Black triangles indicate that iridescent coloration and/or wax-based whitish color are recognized although UV reflection has not been investigated. (B) Examples of reflectance of iridescent dorsal wing coloration based on Schultz and Fincke (2009), Stavenga et al. (2012), and Guillermo-Ferreira et al. (2015, 2019). (C) Examples of reflectance of wax-based coloration based on Schultz and Fincke (2009) and Futahashi et al. (2019). (D) Examples of reflectance of pigment-based thoracic pale coloration based on Henze et al. (2019). (E-J) Bright field and green fluorescence images of yellow-white coloration in Odonata. (E,F) Thorax of Tanypteryx pryeri male. (G,H) An enlarged region of a hindleg of $P$. foliacea male. (I,J) Pseudopterostigma of C. japonica female. 
thorax and abdomen is detected in several families, such as Aeshnidae (Harris et al., 2011; Figures 1J,L, arrows). The surface wax can be removed by rubbing and dissolves completely in chloroform (Schultz and Fincke, 2009; Guillermo-Ferreira et al., 2015, 2019; Futahashi et al., 2019).

In Libellulidae dragonflies, the abdominal surface wax strongly reflects both UV and visible light (Robey, 1975; Silberglied, 1979; Robertson, 1984; Harris et al., 2011; Futahashi et al., 2019). UV photographs confirmed that the whitish surface wax caused UV reflection in all examined species (Figures 1E-G). Based on its fine structure, the abdominal surface wax can be classified into two types, lamellar type (detected in Lestidae and Libellulidae) and filamentous type (detected in Calopterygidae and Euphaeidae) (Gorb, 1995). The sizes of wax lamellae on the abdomen differ between the dorsal and ventral regions as well as between species and sexes (Gorb, 1995; Futahashi et al., 2019). The whitish color of the wax-secreted region temporarily blackens when light scattering is disturbed by the application of acetone, while it irreversibly blackens when the wax is removed by chloroform treatment, suggesting that waxbased fine structures are responsible for the whitish color with UV reflection (Futahashi et al., 2019). The whitish wax also appears on the wing surface of several Odonata species, forming micropillar or filamentous structures (Gorb et al., 2000; Schultz and Fincke, 2009; Guillermo-Ferreira et al., 2015, 2019; Nixon et al., 2017). In the neotropical helicopter damselfly Megaloprepus caerulatus (Coenagrionidae, formerly known as Pseudostigmatidae), white bands on the wings are coated with longer and thicker structures compared to the bluish iridescent and hyaline wing regions (Schultz and Fincke, 2009). Chloroform treatment removes the wax on the wing surface, turning white color into transparent (Schultz and Fincke, 2009).

The reflectance of the dorsal abdomen of Libellulidae species shows that mature males with whitish wax represent a spectrum that decreases gradually from 300 to $700 \mathrm{~nm}$ (Figure 2C; Robertson, 1984; Futahashi et al., 2019). Meanwhile, the dorsal abdomen of mature females (without the pruinose wax) exhibits little UV reflection and mainly reflects light at wavelengths above $500 \mathrm{~nm}$ (Figure 2C; Futahashi et al., 2019). The reflectance of the whitish wing markings shows a flat spectrum (Schultz and Fincke, 2009; Xu and Fincke, 2015; Nixon et al., 2017). In M. caerulatus, sex-specific white bands appear on the wings, and white bands on females exhibit stronger reflection than those on males (Figure 2C; Schultz and Fincke, 2009; Xu and Fincke, 2015).

In the Libellulidae species, chemical analysis has revealed that very long-chain aldehydes and very long-chain methyl ketones are the major components of the abdominal wax. The chemically synthesized compound of very long-chain methyl ketone, which is the main UV-reflective wax component of mature males of Orthetrum albistylum (Libellulidae) (Figure 1G), spontaneously forms light-scattering fine structures with strong UV reflection (Futahashi et al., 2019), suggesting that the secreted very long-chain methyl ketones play a crucial role in UV reflection. The comparative transcriptome in different stages, sexes, and abdominal regions of $O$. albistylum has revealed that the ELOVL17 gene, a member of the elongation of the very long-chain fatty acid (ELOVL) protein family, is specifically expressed in the region where very longchain methyl ketones are present, suggesting that this gene is involved in the production of very long-chain methyl ketones (Futahashi et al., 2019). Wax-based UV reflection has been also reported in several other organisms (Byers, 1975; Pope, 1979); however, the chemical composition of dragonfly abdominal wax differs from previously identified waxes of other organisms. Because the wax-based body color changes in the Libellulidae dragonflies are likely to have evolved independently of those in other Odonata (Figure 2A), further research is needed to determine whether the wax component and the genes involved in wax production are the same in other Odonata species.

\section{EXAMPLES AND MECHANISMS OF PIGMENT-BASED PALE COLOR WITH UV REFLECTION}

Recently, another type of UV reflection has been reported, namely, UV reflection by epidermal granules containing pteridine pigments. UV reflection is generally weak or undetectable in the blue-green, yellow, and white thoracic and abdominal markings of most Odonata species (Figures 1H-P; Hilton, 1986). Notably, UV reflection has been sometimes confirmed in pale-colored regions without whitish wax (Figure 2A; Harris et al., 2011; Henze et al., 2019). For example, in the blue-tailed damselflies Ischnura species (Coenagrionidae), remarkable UV reflection has been recognized in the blue-green thoracic regions of males and andromorphic females only during the immature adult stage, and UV reflection decreases rapidly as they mature (Figures 1I,J, 2D; Henze et al., 2019). Such non-iridescent light blue-green coloration of dragonflies can be explained by coherent scattering due to light-scattering granules containing pteridine pigments in the distal layer of the epidermis and light-absorbing granules containing ommochrome pigments in the proximal layer of the epidermis (Veron, 1974; Prum et al., 2004; Henze et al., 2019). Some pteridine pigments (e.g., leucopterin and xanthopterin) absorb light predominantly in the UV range, and the amount and composition of pteridine pigments cause sex- and species-specific differences in UV reflection in the wings of pierid butterflies (Makino et al., 1952; Stavenga et al., 2004; Rutowski et al., 2005; Giraldo and Stavenga, 2007; Morehouse et al., 2007). In Ischnura damselflies, reflectance at different adult developmental stages is associated with changes in pteridine pigments (probably erythropterin and xanthopterin) within epidermal nanospheres (Henze et al., 2019). The calculated reflectance spectra show that erythropterincontaining nanospheres reflect light with two peaks in the green and UV wavelength range, whereas xanthopterin-containing nanospheres reflect light in the blue wavelength range (Henze et al., 2019), corresponding to the reflectance of immature or mature males, respectively (Figure 2D).

In males of the featherleg damselfly Platycnemis foliacea (Platycnemididae), UV reflection was observed on the white petal-like enlarged regions of the legs, although the central lines of the white legs, whitish thoracic, and abdominal 
markings scarcely reflected UV light (Figure 1H). Moreover, UV reflection was also prominent at the white spot called the pseudopterostigma on the female wings of $C$. japonica (Calopterygidae) (Figure 1D, arrow). Yellowish pigments in Odonata have been considered to be pteridine pigments (Krieger, 1954; Vilela et al., 2017), and pteridine pigments often emit strong fluorescence under UV light (Kayser, 1985). Fluorescence signals were generally observed with yellowish markings (Figures 2E,F), the edge and central line of the white legs of $P$. foliacea (Figures $\mathbf{2 G}, \mathbf{H}$ ), and the wing veins of the pseudopterostigma region of C. japonica (Figures 2I,J), probably due to pteridine pigments. Meanwhile, the fluorescence signals were weak in the UV-reflective regions, such as white petal-like regions on the legs of $P$. foliacea (Figures $\mathbf{2 G}, \mathbf{H}$ ) and the whitish wing membranes in the pseudopterostigma of C. japonica females (Figures 2I,J), suggesting that UV-reflective white colors are probably due to substances other than pteridine pigments. Identification of pigments in various Odonata species deserves future study.

\section{ECOLOGICAL SIGNIFICANCE OF UV REFLECTION AND ABSORPTION}

Since individuals of Odonata species visually recognize each other, body color patterns are generally important for mate recognition and male-male competition. Species with iridescent wings are found mainly in Zygoptera species (Figure 2A). This is likely because Zygoptera species fly more slowly than Anisoptera species (Rüppell, 1989), and species with colored wings often pause their wings during encounters (HilfertRüppell and Rüppell, 2013). Also, courtship behavior is found predominantly in Zygoptera species (e.g., Calopterygidae), as males usually display their iridescent wings to females and rival males (Waage, 1973, 1988; Siva-Jothy, 1999; Hariyama et al., 2005; Nixon et al., 2013; Günther et al., 2014). The reflectance patterns suggest that the UV reflection seems to be important for some Odonata species, such as C. scintillans and $Z$. lanei (Figure 2B). In C. scintillans, the winners of territorial fights have higher values for the wing pigmentation and the hue of the wing's dorsal surface (Guillermo-Ferreira et al., 2019). In Z. lanei, males with distal half of their dorsal wings painted black reduce aggression from rivals, suggesting that iridescent wing coloration is important for male-male competition (Guillermo-Ferreira et al., 2015).

In $M$. caerulatus, both males and females have UV-blue iridescent markings and UV-reflective white bands on their wings (Figures 2B,C), although the position of white bands differs between sexes. Behavioral experiments suggest that the white band pattern on females helps males to distinguish potential mates from rivals (Schultz and Fincke, 2009). When UV reflection is artificially suppressed by using a UV-absorbing sunscreen agent, males with white bands that are less UVreflective are more likely to lose territorial fights, although the UV reflectivity of the female's white bands does not affect the male's mate recognition (Xu and Fincke, 2015). In the damselfly Mnesarete pudica (Calopterygidae), both mature males and mature females have UV-reflective coloration on their wings. Behavioral experiments with reducing UV reflection on their wings show that UV reflection enhances both sexual and aggressive responses, while male-specific red wing pigmentation is important for mate recognition (Guillermo-Ferreira et al., 2014).

Wax-based abdominal color changes are also important for mate recognition and male-male competition in many Odonata species (Jacobs, 1955; Robey, 1975; Corbet, 1999), although it remains unclear whether UV reflection itself is important. Moreover, a wax-based whitish color may help thermoregulation and provide protection against UV-induced damage by reflecting UV radiation (Paulson, 1983; Ubukata, 1985; Futahashi et al., 2019). Species that prefer sunny habitats tend to show stronger UV reflection, like mature males of O. albistylum (Figures 1G, 2C; Paulson, 1983; Futahashi et al., 2019). Given that most dragonfly species with ventral wax in females mate in sunny places without flying (Figure 1F; Sugimura et al., 2001; Ozono et al., 2017), it seems plausible that the UV-reflective wax in females protects the ventral abdomen, including ovaries, from UV damage (Futahashi et al., 2019).

Compared with iridescent coloration and the wax-based whitish color, little study has been conducted about the pigmentdependent differences in UV reflection. It should be noted that males of I. elegans prefer mature females with little UV reflection to immature females (Van Gossum et al., 2001). Males of $P$. foliacea display their enlarged white legs to females, as well as to rival males, and C. japonica males first grab white pseudopterostigmas on the female's wings when connecting with a female (Sugimura et al., 2001; Ozono et al., 2017). The importance of UV reflection in these behaviors should be confirmed experimentally, like $M$. caerulatus and $M$. pudica.

Other than reflection, UV light is absorbed by pigments or transmitted due to absence of pigments. Hilton (1986) reported that the wings transmitted UV light without absorbing or reflecting it in about half of the species examined, and yellow, orange, and brown wing markings generally exhibited UV absorption (Figures 1B-D,F,M-O). Notably, conspicuous UV absorption has been observed in the almost hyaline (very faint yellow to human eyes) wings in some dragonflies, especially in Gomphidae species (Figures 1N,O; Hilton, 1986). Also, these UV absorption patterns often differ between sexes and species. For example, in the dragonfly Phanogomphus hodgesi (Gomphidae), UV light is absorbed in male wings and transmitted in female wings, although both males and females have similar hyaline wings (Hilton, 1986). In the male of Sinogomphus flavolimbatus (Gomphidae), a UV absorption pattern was detected at the base of the wings (Figure 10), which is reminiscent of a UV-absorbing flower nectar guide. These examples suggest that sex- and speciesspecific UV absorption should also be considered for examining the importance of body color.

\section{AUTHOR CONTRIBUTIONS}

The author confirms being the sole contributor of this work and has approved it for publication. 


\section{FUNDING}

The author work was supported by JSPS KAKENHI Grant Numbers JP26660276, JP26711021, JP18H02491, JP18H04893, and JP19H03287.

\section{REFERENCES}

Appel, E., Heepe, L., Lin, C. P., and Gorb, S. N. (2015). Ultrastructure of dragonfly wing veins: composite structure of fibrous material supplemented by resilin. J. Anat. 227, 561-582. doi: 10.1111/joa.12362

Bybee, S., Cordoba-Aguilar, A., Duryea, M. C., Futahashi, R., Hansson, B., LorenzoCarballa, M. O., et al. (2016). Odonata (dragonflies and damselflies) as a bridge between ecology and evolutionary genomics. Front. Zool. 13:46. doi: 10.1186/ s12983-016-0176-7

Byers, J. R. (1975). Tyndall blue and surface white of tent caterpillars, Malacosoma spp. J. Insect Physiol. 21, 401-415. doi: 10.1016/0022-1910(75)90033-5

Corbet, P. S. (1999). Dragonflies, Behavior and Ecology of Odonata. Ithaca: Cornell University Press.

Fitzstephens, D. M., and Getty, T. (2000). Colour, fat and social status in male damselflies, Calopteryx maculata. Anim. Behav. 60, 851-855. doi: 10.1006/anbe. 2000.1548

Futahashi, R. (2016). Color vision and color formation in dragonflies. Curr. Opin. Insect Sci. 17, 32-39. doi: 10.1016/j.cois.2016.05.014

Futahashi, R., Kawahara-Miki, R., Kinoshita, M., Yoshitake, K., Yajima, S., Arikawa, K., et al. (2015). Extraordinary diversity of visual opsin genes in dragonflies. Proc. Natl. Acad. Sci. U.S.A. 112, E1247-E1256.

Futahashi, R., Yamahama, Y., Kawaguchi, M., Mori, N., Ishii, D., Okude, G., et al. (2019). Molecular basis of wax-based color change and UV reflection in dragonflies. eLife 8:e43045.

Giraldo, M. A., and Stavenga, D. G. (2007). Sexual dichroism and pigment localization in the wing scales of Pieris rapae butterflies. Proc Biol Sci. 274, 97-102. doi: 10.1098/rspb.2006.3708

Gorb, S. N. (1995). Scanning electron microscopy of pruinosity in Odonata. Odonatologica 24, 225-228.

Gorb, S. N., Kesel, A., and Berger, J. (2000). Microsculpture of the wing surface in Odonata: evidence for cuticular wax covering. Arthropod. Struct. Dev. 29, 129-135. doi: 10.1016/s1467-8039(00)00020-7

Guillermo-Ferreira, R., Bispo, P. C., Appel, E., Kovalev, A., and Gorb, S. N. (2015). Mechanism of the wing colouration in the dragonfly Zenithoptera lanei (Odonata: Libellulidae) and its role in intraspecific communication. J. Insect Physiol. 81, 129-136. doi: 10.1016/j.jinsphys.2015.07.010

Guillermo-Ferreira, R., Bispo, P. C., Appel, E., Kovalev, A., and Gorb, S. N. (2019) Structural coloration predicts the outcome of male contests in the Amazonian damselfly Chalcopteryx scintillans (Odonata: Polythoridae). Arthropod Struct. Dev. 53:100884. doi: 10.1016/j.asd.2019.100884

Guillermo-Ferreira, R., Therézio, E. M., Gehlen, M. H., Bispo, P. C., and Marletta, A. (2014). The role of wing pigmentation, UV and fluorescence as signals in a Neotropical damselfly. J. Insect Behav. 27, 67-80. doi: 10.1007/s10905-0139406-4

Günther, A., Hilfert-Rüppell, D., and Rüppell, G. (2014). Reproductive behaviour and the system of signalling in Neurobasis chinensis - a kinematic analysis. Int J. Odonatol. 17, 31-52. doi: 10.1080/13887890.2014.881305

Hariyama, T., Hironaka, M., Horiguchi, H., and Stavenga, D. G. (2005). "The leaf beetle, the jewel beetle, and the damselfly; insects with a multilayered show case," in Structural Colors in Biological Systems: Principles and Applications, eds T. Shimozawa and T. Hariyama (Osaka: Osaka University Press), 153-176.

Harris, W. E., Forman, D. W., Battell, R. D., Battell, M. T. R., Nelson, A. K., and Brain, P. F. (2011). Odonata colour: more than meets the eye? Int. J. Odonatol. $14,281-289$.

Henze, M. J., Lind, O., Wilts, B. D., and Kelber, A. (2019). Pterin-pigmented nanospheres create the colours of the polymorphic damselfly Ischnura elegans. J. R. Soc. Interface 16:20180785. doi: 10.1098/rsif.2018.0785

Hilfert-Rüppell, D., and Rüppell, G. (2013). Do coloured-winged damselflies and dragonflies have flight kinematics different from those with clear wings? Int. J. Odonatol. 16, 119-134. doi: 10.1080/13887890.2013.763332

\section{ACKNOWLEDGMENTS}

I would like to thank Tohru Usui for technical advice on taking UV photographs, and Genta Okude, Mizuko Osanai-Futahashi, and two reviewers for helpful comments of the manuscript.

Hilton, D. F. J. (1986). A survey of some Odonata for ultraviolet patterns. Odonatologica $15,335-345$.

Huang, S. C., Chiou, T. H., Marshall, J., and Reinhard, J. (2014). Spectral sensitivities and color signals in a polymorphic damselfly. PLoS One 9:e87972. doi: 10.1371/journal.pone.0087972

Jacobs, M. E. (1955). Studies on territorialism and sexual selection in dragonflies. Ecology 36, 566-586. doi: 10.2307/1931296

Kayser, H. (1985). "Pigments," in Comprehensive Insect Physiology, Biochemistry and Pharmacology, eds G. A. Kerkut and L. I. Gilbert (New York, NY: Pergamon), 367-415.

Kinoshita, S., and Yoshioka, S. (2005). Structural colors in nature: the role of regularity and irregularity in the structure. Chem. Phys. Chem. 6, 1442-1459. doi: $10.1002 /$ cphc. 200500007

Krieger, F. (1954). Untersuchungen über den Farbwechsel der Libellenlarven Z. vergl. Physiology 36, 352-366. doi: 10.1007/bf00345026

Kuitunen, K., and Gorb, S. N. (2011). Effects of cuticle structure and crystalline wax coverage on the coloration in young and old males of Calopteryx splendens and Calopteryx virgo. Zoology 114, 129-139. doi: 10.1016/j.zool.2011.01.003

Labhart, T., and Nilsson, D. E. (1995). The dorsal eye of the dragonfly Sympetrum: specializations for prey detection against the blue sky. J. Comp. Physiol. A 176 437-453.

Makino, K., Satoh, K., Koike, M., and Ueno, N. (1952). Sex in Pieris rapae L. and the pteridin content of their wings. Nature 170, 933-934. doi: 10.1038/170933a0

Meinertzhagen, I. A., Menzel, R., and Kahle, G. (1983). The identification of spectral receptor types in the retina and lamina of the dragonfly Sympetrum rubicundulum. J. Comp. Physiol. 15, 295-310. doi: 10.1007/bf00623906

Morehouse, N. I., Vukusic, P., and Rutowski, R. (2007). Pterin pigment granules are responsible for both broadband light scattering and wavelength selective absorption in the wing scales of pierid butterflies. Proc. Biol. Sci. 274, 359-366. doi: $10.1098 / \mathrm{rspb} .2006 .3730$

Nixon, M. R., Orr, A. G., and Vukusic, P. (2013). Subtle design changes control the difference in colour reflection from the dorsal and ventral wing-membrane surfaces of the damselfly Matronoides cyaneipennis. Opt. Express 21, 1479-1488.

Nixon, M. R., Orr, A. G., and Vukusic, P. (2015). Wrinkles enhance the diffuse reflection from the dragonfly Rhyothemis resplendens. J. R. Soc. Interface 12:20140749. doi: 10.1098/rsif.2014.0749

Nixon, M. R., Orr, A. G., and Vukusic, P. (2017). Covert linear polarization signatures from brilliant white two-dimensional disordered wing structures of the phoenix damselfly. J. R. Soc. Interface 14:20170036. doi: 10.1098/rsif.2017. 0036

Ozono, A., Kawashima, I., and Futahashi, R. (2017). Dragonflies of Japan, 3rd Edn. Tokyo: Bunichi-Sogo Syuppan, Co Ltd.

Paulson, D. R. (1983). A new species of dragonfly Gomphus (Gomphunis) lynnae sp. nov. from the Yakima River, Washington, with notes on pruinosity in Gomphidae (Anisoptera). Odonatologica 12, 59-70.

Pope, R. D. (1979). Wax production by coccinellid larvae (Coleoptera). Syst. Entomol. 4, 171-196. doi: 10.1111/j.1365-3113.1979.tb00632.x

Prum, R. O., Cole, J. A., and Torres, R. H. (2004). Blue integumentary structural colours in dragonflies (Odonata) are not produced by incoherent Tyndall scattering. J. Exp. Biol. 207, 3999-4009. doi: 10.1242/jeb.01240

Robertson, H. M. (1984). Pruinosity in odonates reflects UV. Nolul. Odonatol. 2, 68-69.

Robey, C. W. (1975). Observations on breeding behavior of Pachydiplax longipennis (Odonata: Libellulidae). Psyche 82, 89-96.

Rüppell, G. (1989). Kinematic analysis of symmetrical flight manoeuvres of Odonata. J. Exp. Biol. 144, 13-42.

Rutowski, R. L., Macedonia, J. M., Morehouse, N., and Taylor-Taft, L. (2005). Pterin pigments amplify iridescent ultraviolet signal in males of the orange sulphur butterfly, Colias eurytheme. Proc. Biol. Sci. 272, 2329-2335. doi: 10.1098/rspb. 2005.3216 
Schultz, T., and Fincke, O. (2009). Structural colours create a flashing cue for sexual recognition and male quality in a Neotropical giant damselfly. Funct. Ecol. 23, 724-732. doi: 10.1111/j.1365-2435.2009.01584.x

Silberglied, R. E. (1979). Communication in the ultraviolet. Ann. Rev. Ecol. Syst. 10, 373-398.

Siva-Jothy, M. T. (1999). Male wing pigmentation may affect reproductive success via female choice in a calopterygid damselfly (Zygoptera). Behaviour 136, 1365-1377. doi: 10.1163/156853999500776

Stavenga, D. G., Leertouwer, H. L., Hariyama, T., De Raedt, H. A., and Wilts, B. D. (2012). Sexual dichromatism of the damselfly Calopteryx japonica caused by a melanin-chitin multilayer in the male wing veins. PLoS One 7:e49743. doi: 10.1371/journal.pone.0049743

Stavenga, D. G., Stowe, S., Siebke, K., Zeil, J., and Arikawa, K. (2004). Butterfly wing colours: scale beads make white pierid wings brighter. Proc. R. Soc. B. 271, 1577-1584. doi: 10.1098/rspb.2004.2781

Stavenga, D. G., Wilts, B. D., Leertouwer, H. L., and Hariyama, T. (2011). Polarized iridescence of the multilayered elytra of the Japanese jewel beetle, Chrysochroa fulgidissima. Philos. Trans. R. Soc. Lond. B 366, 709-723. doi: 10.1098/rstb.2010. 0197

Sugimura, M., Ishida, S., Kojima, K., Ishida, K., and Aoki, T. (2001). Dragonflies of the Japanese Archipelago in Color. Sapporo: Hokkaido Univ Press.

Suvorov, A., Jensen, N. O., Sharkey, C. R., Fujimoto, M. S., Bodily, P., Wightman, H. M., et al. (2017). Opsins have evolved under the permanent heterozygote model: insights from phylotranscriptomics of Odonata. Mol. Ecol. 26, 13061322. doi: $10.1111 / \mathrm{mec} .13884$

Tillyard, R. J. (1917). The Biology of Dragonflies. Cambridge, MA: Cambridge Univ Press.

Ubukata, H. (1985). The Odonata collected at Mt. Taisetsu in 1984, with a discussion on the pruinescent female of Orthetrum albistylum speciosum. Silvicola 3, 23-26.

Van Gossum, H., Stoks, R., and De Bruyn, L. (2001). Discriminative mate choice in relation with female maturation in Ischnura elegans (Odonata: Coenagrionidae). Int. J. Odonatol. 4, 83-91. doi: 10.1080/13887890.2001. 9748161
Veron, J. E. (1974). Physiological colour changes in Odonata eyes. A comparison between eye and epidermal chromatophore pigment migrations. J. Insect Physiol. 20, 1491-1505. doi: 10.1016/0022-1910(74)90081-x

Vilela, D. S., Tosta, T. A. A., Rodrigues, R. R., Del-Claro, K., and GuillermoFerreira, R. (2017). Colours of war: visual signals may influence the outcome of territorial contests in the tiger damselfly, Tigriagrion aurantinigrum. Biol. J. Linn. Soc. 121, 786-795. doi: 10.1093/biolinnean/blx024

Vukusic, P., Wootton, R. J., and Sambles, J. R. (2004). Remarkable iridescence in the hindwings of the damselfly Neurobasis chinensis chinensis (Linnaeus) (Zygoptera: Calopterygidae). Proc. Biol. Sci. 271, 595-601. doi: 10.1098/rspb. 2003.2595

Waage, J. K. (1973). Reproductive behavior and its relation to territoriality in Calopteryx maculata (Beauvois) (Odonata: Calopterygidae). Behaviour 47, 240 256. doi: 10.1163/156853973x00094

Waage, J. K. (1988). Confusion over residency and the escalation of damselfly territorial disputes. Anim. Behav. 36, 586-595. doi: 10.1016/s0003-3472(88) 80030-7

Xu, M., and Fincke, O. M. (2015). Ultraviolet wing signal affects territorial contest outcome in a sexually dimorphic damselfly. Anim. Behav. 101, 67-74. doi: 10.1016/j.anbehav.2014.12.018

Yang, E. C., and Osorio, D. (1991). Spectral sensitivities of photoreceptors and lamina monopolar cells in the dragonfly, Hemicordulia tau. J. Comp. Physiol. A 169, 663-669.

Conflict of Interest: The author declares that the research was conducted in the absence of any commercial or financial relationships that could be construed as a potential conflict of interest.

Copyright (C) 2020 Futahashi. This is an open-access article distributed under the terms of the Creative Commons Attribution License (CC BY). The use, distribution or reproduction in other forums is permitted, provided the original author(s) and the copyright owner(s) are credited and that the original publication in this journal is cited, in accordance with accepted academic practice. No use, distribution or reproduction is permitted which does not comply with these terms. 